\section{Semidwarf Growth Habit in Clingstone Peach with Desirable Tree and Fruit Qualities}

\author{
T.M. Gradziel and W. Beres \\ Department of Pomology, University of California, Davis, CA 95616 \\ Additional index words. breeding, dwarf, genetics, high density, Prunus persica
}

\begin{abstract}
A single seedling exhibiting a semidwarf growth habit was found in an openpollinated clingstone peach [Prunus persica (L.) Batsch] population. The growth habit was upright and open, with short, spur-like lateral branching. Tree size was about half that of its siblings as a result of shorter internodes. The total number of nodes on first-order branches was not significantly different from that on standard-sized trees. The semidwarf growth habit remained stable after vegetative propagation. Segregation in sexual progeny showed the trait to be highly heritable.
\end{abstract}

The average planting density for new clingstone peach orchards has increased from $\approx 275$ trees/ha in 1983 to $\approx 500$ trees/ha in 1989 (California Canning Peach Association, 1990). High-density plantings produce higher yields per unit area of young orchards and may improve net returns over the orchard's life (Chalmers et al., 1981). Tree-to-tree competition in high-density plantings causes reduced tree size, a characteristic that facilitates orchard operations and may reduce liability insurance premiums if ladders are not required.

Third-leaf yields of advanced clingstone peach selections have been $>40 \mathrm{t} \cdot \mathrm{ha}^{-1}$ in commercial high-density cordon-type systems. However, the extensive input demanded by this type of system to control vegetative growth has limited its acceptance. Dormant and summer pruning are used to limit tree size in trellis and hedge-row plantings (Hayden and Emerson, 1979; Phillips and Weaver, 1975). Breeding reduced-stature cultivars adapted to high-density systems would reduce pruning costs-one of the largest expenses in clingstone peach production.

High-density systems have been developed in apple (Malus domestica Borkh.) using dwarfing rootstock. Commercially acceptable dwarfing rootstock for clingstone peach are not yet available. Well-characterized scion genotypes that confer reduced shoot stature include brachytic dwarf $(d w d w)$ and compact $(C t-)$. A brachytic dwarf phenotype has very short internodes and dense foliage with poor light penetration (Scorza, 1984). A compact phenotype has a dense branching pattern, an intermediate internode length, bushy growth habit, and a densely pubescent fruit often with poor color and sugar content (Mehlenbacher and Scorza, 1986). Brachytic dwarf and compact genotypes have been used to develop

Received for publication 12 Aug. 1992. Accepted for publication 23 Aug. 1993. The California Cling Peach Advisory Board supported this research. The cost of publishing this paper was defrayed in part by the payment of page charges. Under postal regulations, this paper therefore must be hereby marked advertisement solely to indicate this fact. reduced-stature peach breeding lines (Hansche and Beres, 1980, Mehlenbacher and Scorza, 1986). Increased emphasis also has been given to developing semidwarf genotypes (Fideghelli et al., 1983).

As part of a clingstone peach cultivar development program, we have identified and evaluated more than 30 seedling selections with a semidwarf growth habit, which is defined as having a mean shoot length $30 \%$ to $50 \%$ shorter than that of the standards. The most promising of these semidwarves is SD2259. SD22-59 also has desirable qualities for a

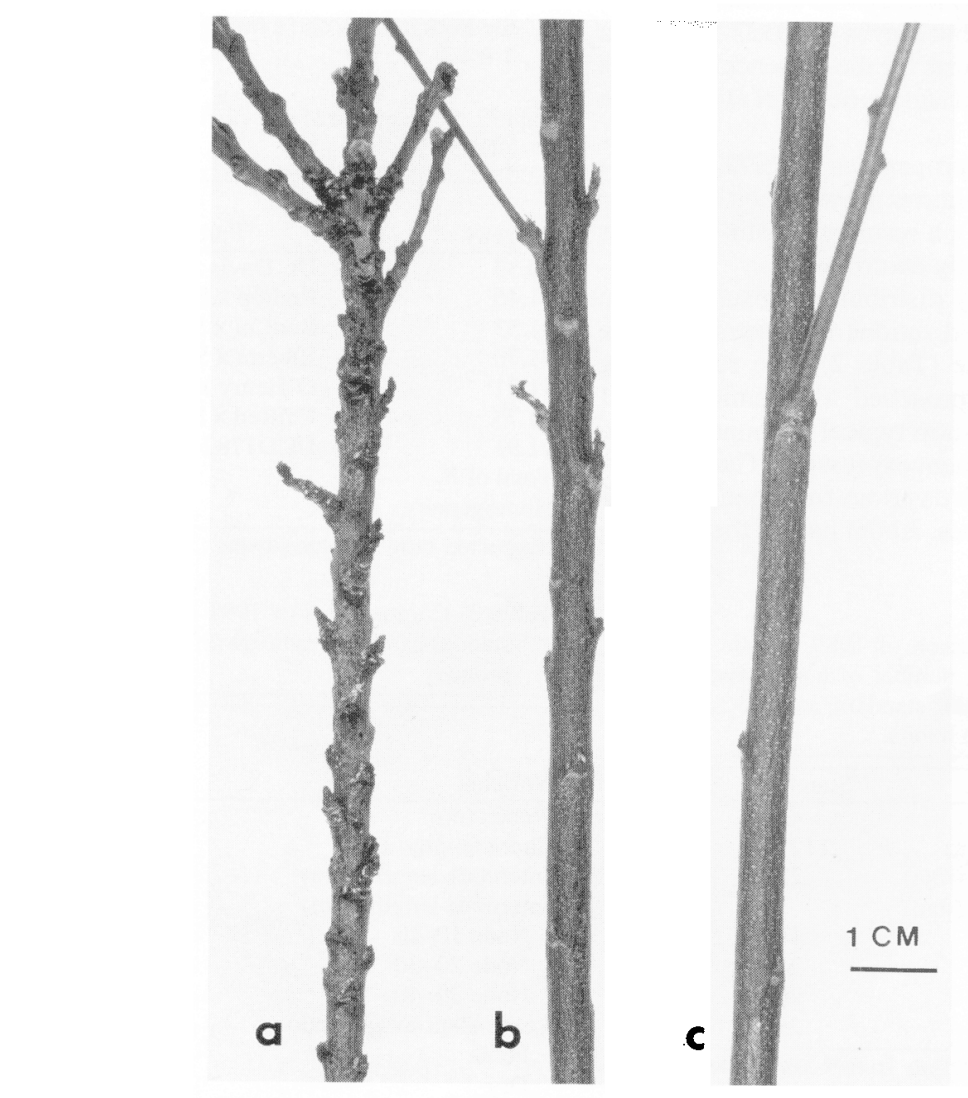

Fig. 1. Shoot internode and branching habit for (a) a homozygous brachytic dwarf peach seedling, (b) the

semidwarf selection SD22-59, and (c) a peach seedling with standard growth habit. mechanically harvestable processing peach, including vigorous yet sturdy growth with an open and upright branching pattern. This paper describes research to characterize the morphology and growth habit of this selection to assess its potential use in high-density plantings. Preliminary evaluations of the inheritance of SD22-59's semidwarf growth habit and fruit quality are presented so that the potential breeding value can be appraised.

Plant materials. The growth habits of SD2259 and its seedling progeny were evaluated. Standard-sized clingstone peach breeding lines and selections homozygous for $d w$ were included for reference. All trees were either seedlings or vegetative propagations in their second growing season, unless otherwise indicated. Propagated items were on Nemaguard rootstock.

Growth habit. Current-season growth, including shoot length and number of nodes to the most recent, fully expanded leaf, was evaluated at the end of the growing season. The basal 10 nodes were excluded because this early season growth often is irregular. Remaining shoot length was partitioned into 10node sections beginning at the base (node 10). At least five first-order shoots (i.e., those originating from the scaffold) from SD22-59 and each of four flanking siblings in the original seedling row were measured in 1989. Trees were thinned to a moderate-sized crop before pit hardening. A minimum of six first-order shoots was measured for each SD22-59 progeny tree and each vegetatively propagated 
selection evaluated in 1991. Leaf : stem ratios, based on fresh- and dry-weight calculations, were determined by weighing leaves plus petioles and stems separately.

Inheritance studies. Controlled hybridizations and hybrid seed preparation and planting were performed in 1990 and 1991, following standard procedures (Hesse, 1975). SD22-59 was the pollen parent in all crosses. Seeds were stratified for 60 days before being planted. Resulting progeny were evaluated for tree size after 1 and 4 months and at the end of the first growing season. Brachytic dwarf seedlings were included as references for the dwarf growth habit. Standard growth habits were determined by measuring seedlings and vegetatively propagated selections known to lack major size-reduction genes.

The original SD22-59 seedling tree was an open-pollinated seedling of the Univ. of California clingstone peach breeding line 18,8-11. At the end of the third growing season, this seedling tree was about half the height of adjacently planted standard-sized siblings. The growth habit was upright. Lateral branches often were short, giving the tree a spur-like appearance. The reduced tree size was due primarily to shorter internodes (Fig. 1), especially evident in basal, early season growth. Internode length of subsequent growth was about double the initial length but remained about half that of adjacent, standard-sized siblings (Table 1). Mean internode length for the entire growing season also was about half that of standard growth habits. The total number of nodes and leaves was similar to that of standard trees, but leaves of SD22-59 were a darker green. Tests for the presence of prunus necrotic ringspot and prune dwarf viruses were negative.

Vegetative propagules of SD22-59 continue to have a shorter growth habit after three seasons (Fig. 2), a result suggesting that this trait is genetically controlled.

The progeny distributions resulting from controlled hybridizations demonstrate that the trait is heritable (Table 2). The segregating populations approached a 1 semidwarf : 1 standard plant ratio typical of monogenic incomplete dominant expression. The seed parents used included various freestone and clingstone peach types. About half of the resulting

Table 1. Comparison of 1989 sample means for shoot length, number of nodes, and internode length between standard and SD22-59 semidwarf growth habits.

\begin{tabular}{lrc}
\hline Variable & Standard & Semidwarf \\
\hline Nodes (no.) & 45 & $43^{\text {*s }}$ \\
Shoot length (mm) & 1125 & $\mathbf{6 0 2}^{* *}$ \\
Internode length $(\mathrm{mm})$ & 25 & $\mathbf{1 4}^{* *}$ \\
Internode length $(\mathrm{mm})^{\mathrm{z}}$ & & \\
$\quad$ Node 10-20 & 18 & $\mathbf{8}^{* *}$ \\
$\quad$ Node 20-30 & 26 & $14^{* * *}$ \\
Node 30-40 & 26 & $17^{* *}$ \\
Node 40-50 & 28 & $16^{* *}$ \\
\hline
\end{tabular}

${ }^{2}$ Measured by section from basal node 10 to the youngest fully expanded leaf.

${ }_{\text {Ns, }}$ "* Nonsignificant or significant at $P \leq 0.01$, respectively, by $t$ test. seedlings expressed the desired semidwarf phenotype, regardless of seed parent.

Significant differences among growth habits were observed in 1991 for internode and shoot length (Table 3), which are two of the factors identified by Scorza (1984) as key growth-habit determinants. Growth-habit determinations made at the end of the first and second growing seasons agreed with those made at 1 and 4 months after planting. The ability to identify growth habit precociously at seedling stage greatly facilitates tree breeding. Fideghelli et al. (1983) reported precocious identification to be particularly difficult with other semidwarf genotypes studied.

Monet and Salesses (1975) briefly described a semidwarf mutant, $A 72$, in the $F_{2}$ generation of the cross of the French freestone peach breeding lines Gf305 $\times$ S.300. The reported growth habit of A72 was similar to that of SD22-59. Selfed A72 progeny segregated in the expected monogenic, semidominant ratio of 1 dwarf : 2 semidwarf : 1 standard, and the symbol " $n$ " has been proposed for this locus. Connors (1922) mentioned a dwarf freestone peach resulting from a chance mutation

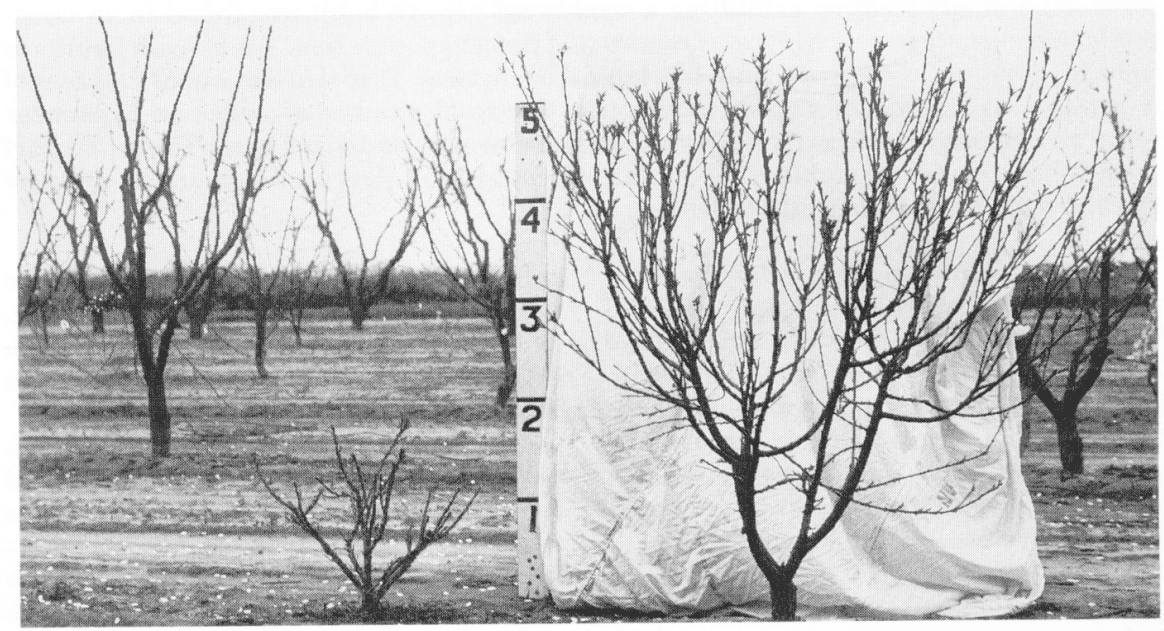

Fig. 2. A budded, nonpruned tree of the semidwarf clingstone peach selection SD22-59 (with white backdrop) at the beginning of fourth leaf. Pruned, standard-sized peach cultivars of identical age are in the background, and a brachytic dwarf selection is to the immediate left of SD22-59. (Scale is in feet; $1 \mathrm{ft}=0.305 \mathrm{~m}$ ).

Table 2. Segregation of growth habit in $F_{1}$ progeny from standard selections crossed to semidwarf selection SD22-59.

\begin{tabular}{llcccc}
\hline & \multicolumn{2}{c}{ Observed growth habit } & Chi & \\
\cline { 3 - 6 } Progeny & Parentage & Semidwarf & Standard & square $^{z}$ & Probability $^{-}$ \\
\hline 90.33 & Dr. Davis X SD22-59 & 40 & 58 & 3.31 & $0.05-0.10$ \\
91.46 & Redtop X SD22-59 & 8 & 11 & 0.47 & $0.40-0.50$ \\
91.53 & RedCal X SD22-59 & 19 & 16 & 0.26 & $0.60-0.70$ \\
91.70 & Elberta X SD22-59 & 7 & 7 & 0.00 & 1.00 \\
91.71 & O'Henry X SD22-59 & 22 & 19 & 0.22 & $0.60-0.70$ \\
91.73 & CalRed X SD22-59 & 22 & 24 & 0.09 & $0.70-0.80$ \\
91.91 & UCD17824 X SD22-59 & 8 & 11 & 0.47 & $0.40-0.50$ \\
Total of F & & 126 & 146 & 1.47 & $0.20-0.30$ \\
Homogeneity & & & & 3.36 & $0.70-0.80$ \\
\hline
\end{tabular}

${ }^{2}$ Expected ratio is 1 semidwarf : 1 standard.

Table 3. Comparisons of 1991 sample means for shoot characteristics and leaf : stem weight ratios of standard and brachytic dwarf items with semidwarf selection SD22-59 and its semidwarf and standard progeny.

\begin{tabular}{|c|c|c|c|c|c|}
\hline Variable & $\begin{array}{c}\text { Brachytic } \\
\text { dwarf }\end{array}$ & $\begin{array}{c}\text { Semidwarf } \\
\text { progeny }\end{array}$ & $\begin{array}{c}\text { Grafted } \\
\text { SD22-59 } \\
\text { parent }\end{array}$ & $\begin{array}{c}\text { Standard } \\
\text { progeny }\end{array}$ & $\begin{array}{l}\text { Grafted } \\
\text { standard } \\
\text { cultivar }\end{array}$ \\
\hline Nodes (no.) & $24.3 \mathrm{a}^{2}$ & $31.8 \mathrm{~b}$ & $32.1 \mathrm{~b}$ & $33.2 \mathrm{~b}$ & $33.5 \mathrm{~b}$ \\
\hline Shoot length (mm) & $108 \mathrm{a}$ & $315 b$ & $334 \mathrm{~b}$ & $712 \mathrm{c}$ & $789 c$ \\
\hline Internode length (mm) & $4 \mathrm{a}$ & $10 \mathrm{~b}$ & $10 b$ & $22 \mathrm{c}$ & $24 \mathrm{c}$ \\
\hline \multicolumn{6}{|l|}{ Internode length $(\mathrm{mm})^{y}$} \\
\hline Node $10-20$ & 3 & 7 & 7 & 23 & 27 \\
\hline Node $20-30$ & 5 & 11 & 12 & 25 & 27 \\
\hline Node $30-40$ & & 12 & 13 & 15 & 18 \\
\hline \multicolumn{6}{|l|}{ Leaf : stem weight ratio } \\
\hline Fresh & $11.5 \mathrm{a}$ & $6.5 \mathrm{~b}$ & $6.4 \mathrm{~b}$ & $2.6 \mathrm{c}$ & $2.2 \mathrm{c}$ \\
\hline Dry & $18.4 \mathrm{a}$ & $7.4 \mathrm{~b}$ & $7.7 \mathrm{~b}$ & $3.1 \mathrm{c}$ & $2.6 \mathrm{c}$ \\
\hline
\end{tabular}

'Mean separation in rows by Duncan's multiple range test, $P \leq 0.05$.

Measured by section from basal node 10 to the youngest fully expanded leaf. 
of 'Elberta'. 'Elbertita', a semidwarf clingstone with short internodes and very darkgreen foliage, has been reported by Hough and Bailey (1958) to be an open-pollinated seedling of a dwarf mutation of 'Elberta'. The gene controlling this dwarfing habit has not been characterized fully, although R. Scorza (personal communication) believes that it is identical to Ct-. Lammerts ( 1945) reported a semidwarf peach trait that was inherited as a double recessive gene $\left(b u_{1} b u_{1} b u_{2} b u_{2}\right)$; either factor acting alone had no appreciable effect. Lammerts also described the semidwarf phenotype as bushy and compact, growing to a height of only $1 \mathrm{~m}$ in 2 years. SD22-59 can be distinguished from compact by growth habit. The dominant expression of SD22-59 also differentiates it from the brachytic dwarf and Lammerts' semidwarf genotypes.

The lineage of SD22-59 (Fig. 3) seems to be distinct from the French material, but SD2259 may be an independent occurrence of the same mutation. No other semidwarf growth habits of this type were observed in $>200$ selfed progeny of the 18,8-11 parent and $>300$ selfed progeny of the 'Riegels' grandparent.

High leaf : stem fresh and dry weight ratios were produced by the SD22-59 parent and its semidwarf progeny (Table 3). The higher leaf : stem ratios and the darker pigmentation may improve cropping efficiencies (DeJong and
Doyle, 1984). SD22-59's open growth habit and intermediate internode length results in considerably less leaf shading than that which occurs in brachytic dwarf homozygotes.

No detrimental effect of the semidwarf growth habit on fruit quality has been detected. SD22-59 fruit were rated good to very good in 1990 and 1991 sensory evaluations of shape, color, firmness, and flavor of processed peach halves (unpublished data). Poor fruit set is common on second-leaf trees, apparently because of leaf crowding on the developing scaffolds. Improved sets occur on subsequently developing laterals. The shoots of SD22-59 and its semidwarf progeny are thicker than those of standard trees, a characteristic resulting in a stiffer branch. Such rigidness is desirable when trees are mechanically harvested with limb shaking equipment, as the force is transferred more efficiently to fruit-bearing terminal wood. The succulent terminal growth, however, seems prone to the peach twig borer (Anarsia lineatella Zell.).

The reduced tree size, while retaining good fruit and branch characteristics without a significant loss in leaf and fruit nodes, has made this genotype useful for evaluating tree architectures and management strategies for highdensity orchards. The concentrated growth, upright and open growth habit, and restricted length of second- and third-order branching

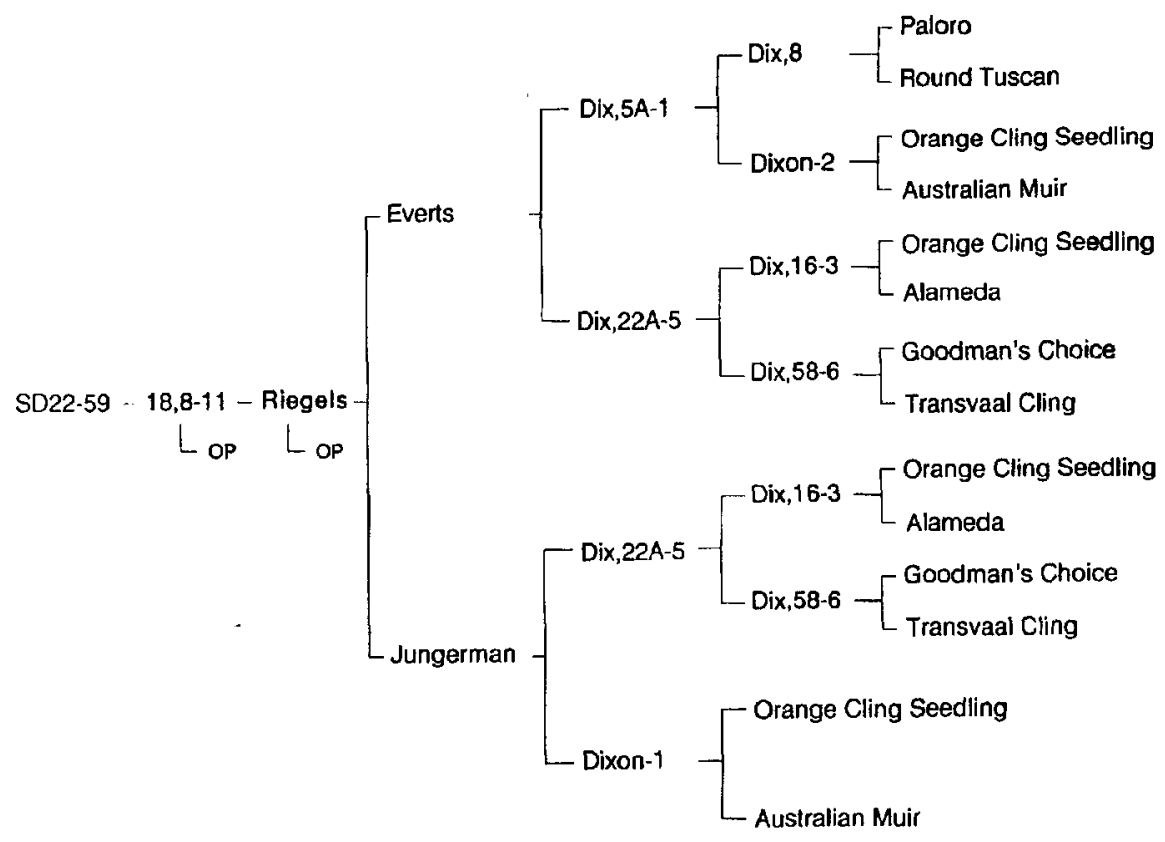

Fig. 3. SD22-59 pedigree. OP = open-pollinated. The seed parent is listed at the top. characteristic of SD22-59 seem well suited to high-density systems such as the Kearney perpendicular-V system arrangement (DeJong, 1988), where the tree's natural growth habit helps control its size. The high heritability and ability to screen for this trait at the seedling stage has facilitated its use in breeding cultivars with different ripening times and increased processing yield through a recurrent backcross program.

\section{Literature Cited}

California Canning Peach Association. 1990. Annual report. California Canning Peach Assn., San Francisco.

Chalmers, D.J., P.D. Mitchell, and L. van Heek. 1981. Control of peach tree growth and productivity by regulated water supply, tree density, and summer pruning. J. Amer. Soc. Hort. Sci. 106:307-312.

Connors, C.H. 1922. Peach breeding-A summary of results. Proc. Amer. Soc. Hort. Sci. 19:108115.

DeJong. T.M. 1988. Peach planting/training systems in California. In: N.F. Childers and W.B Sherman (eds.). The peach. Somerset Press, Somerville, N.J. p. 418-423.

DeJong, T.M. and J.F. Doyle. 1984. Cropping efficiency, dry matter and nitrogen distribution in mature genetic dwarf and standard peach trees. Acta. Hort. 146:89-95.

Fideghelli, C., R. Quarta, G. Della Strada, and M.T. Dettori. 1983. Tree and fruit characteristics of several genetic semidwarf peach selections. Acta Hort. 140:119-124.

Hansche, P.E. and W. Beres. 1980. Genetic remodeling of fruit and nut trees to facilitate cultivar improvement. HortScience 15:710-715.

Hayden, R.A. and F.H. Emerson. 1979. Pruning high density peach hedge plantings. Compact Fruit Tree 12:76-78.

Hesse, C.O. 1975. Peaches. In: J. Janick and J.N. Moore (eds.). Advances in fruit breeding. Purdue Univ. Press, West Lafayette, Ind.

Hough, L.F. and C.H. Bailey. 1958. Elbertita-A dwarf peach for home gardens. Fruit Var. Hort. Dig. 12:60.

Lammerts, W.E. 1945. The breeding of ornamental edible peaches for mild climates. I. Inheritance of tree and flower characteristics. Amer. J. Bot. 32:53-61.

Mehlenbacher, S.A. and R. Scorza. 1986. Inheritance of growth habit in progenies of 'Compact Redhaven' peach. HortScience 21:124-126.

Monet, R. and G. Salesses. 1975. Un nouveau mutant de nanisme chez le pêcher. Ann. Amelior. Plantes 25:353-359.

Phillips, J.H.H. and G.M. Weaver. 1975. A highdensity peach orchard. HortScience 10:580582.

Scorza, R. 1984. Characterization of four distinct peach tree growth types. J. Amer. Soc. Hort. Sci. 109:455-457. 